\title{
Review on Antibody as A Drug of Choice
}

\author{
"Lama Yimer, Kumsisa Mideksa, Beshatu Ferede \\ Wollega University, School of Veterinary Medicine, P.O. Box: 395, Nekemte, Ethiopia
}

"Corresponding author: Lama Yimer, Wollega University, School of Veterinary Medicine, P.O. Box: 395, Nekemte, Ethiopia; Tel: +251917081237; E-mail: lemayimer@gmail.com

Citation: Yimer L, Mideksa K, Ferede B (2017) Review on Antibody as a Drug of Choice. Arch Vet Sci, 2017: VST112. DOI:10.29011/AVST-112/100012

Received Date: 12 April, 2017: Accepted Date: 17 April, 2017: Published Date: 24 April, 2017

\begin{abstract}
During the last 20 years, infectious diseases have indeed made a staggering comeback for a variety of reasons, including resistance against existing antibiotics. As a consequence, several alternatives to antibiotics are currently being considered or reconsidered. The modification of antibodies is of major interest since changes in their functionality and physico-chemical properties will broaden their application area. The features that make antibodies attractive drug candidates are high target specificity and their organization into distinct structural and functional domains. Antibody therapy has an increasing number of applications in which it is possible to use inexpensive sources of animal antibodies, such as bovine colostral antibodies and egg yolk antibodies. A powerful way to fight infections in our days will be to use immune system as complement or replacement to antibiotics. The immune system and microorganisms have coexisted for millions of years and microorganisms have not become resistant towards them. But, its use is less than expected value still in developing countries including Ethiopia. Therefore, it is better if therapeutic and prophylactic antibodies are considered rather than antibiotics.
\end{abstract}

Keywords: Antibiotics, Antibody, Antigen, Immunity.

\section{Introduction}

The big load of antimicrobials (Antibiotics, Antimycotics and Antivirals) given both to man and animals is a threat to our environment with the menace to give a total imbalance between microbial species in humans, animals, plants, water and soil. Antibiotics are today found ubiquitous in our environment in constantly growing amounts and given to animals as "Growth Factors" especially to piglets, calves and chickens to avoid weaning diarrhea and to promote growth [1].

Antibiotics are distributed everywhere in animals and humans: blood, flesh, urine and faces. Antibiotic contaminated flesh is eaten both by humans and animals. Then, it excreted to the environment by urine and faces. Antibiotic factories spread out tons of antibiotics from their plants. Unused antibiotics are thrown away. Soil and water are enormous reservoirs for antibiotics. Soildwelling microbes encounter a myriad of antibiotics mostly in low concentrations. Low concentrations do not kill bacteria, but they will evolve strategies to resistance. Genetic spread of multidrug resistant bacteria is the biggest problem for propagation of antibiotic resistance [2]. However, the best defense for humans, mammals and birds against all kind of infectious agents has always been the immune system. A powerful way to fight infections in our days will be to use this system as complement or replacement to antibiotics. Antibodies have a high specificity for binding and inactivating foreign substances including different microbes (Bacteria, Viruses, Fungi, and Protozoa). All mammals produce antibodies [3].

Antibodies are simply soluble forms of B- cell receptor secreted in to body fluids by activated B-cell that is used by immune system to identify and neutralize foreign objects such as bacteria and viruses; they all belong to the class of proteins called immunoglobulins. An antibody, also known as an immunoglobulin, is a large Y-shaped glycoprotein. Each of its tips contains a paratope that is specific for one particular epitope on an antigen, allowing these two structures to bind together with precision [4]. Using this binding mechanism, an antibody can tag a microbe or an infected cell for attack by other parts of the immune system, or can neutralize its target directly. The production of antibodies is the main function of the humeral immune system [5]. B cell receptor is only found on the surface of B cells and facilitates the activation of these cells and their subsequent differentiation into either antibody factories called plasma cells, or memory B cells that will survive in the body and remember the same antigen, so that the B cells can respond faster upon future exposure [6].

One of the main functions of fixation of complement is that lysis of cells and release of biologically active molecules. Another important function is binding to various cell types; phago- 
cytic cells, lymphocytes, platelets, mast cells, and basophils have receptors that bind immunoglobulins newborn [4]. Now a days, scientists are using transgenic animals and plants to produce specific antibodies and are showing an innovative promise in future to solve many disease cost problems both in animal and human. However, the use and industrial production of monoclonal antibodies through the application of antibody engineering is still less than the expected value, mostly in developing countries including Ethiopia [7].

Therefore, the main objectives of this seminar paper are:

- To review and provide information on the therapeutic and prophylactic use of antibody

- To describe the maternal extension of antibodies

- To review and describe some application of antibody engineering.

\section{An Overview on Antibody Therapies}

\section{General concept about Antibody}

The typical Y-shaped structure of an antibody molecule consists of two identical heavy $(\mathrm{H})$ and two identical light (L) chains, linked by disulfide bonds. All four chains consist of constant (C) and variable $(\mathrm{V})$ domains. The lower part of the molecule, called the $\mathrm{Fc}$ region, is highly conserved between antibody classes, and mediates effector functions of antibodies. The upper arms of the antibody are referred to Fab regions. The $\mathrm{V}$ regions of both heavy and light chains combine to form two identical antigen binding sites. Within each $\mathrm{V}$ domain, amino acid sequence variation, and hence antigen recognition, is predominantly focused around three "hyper variable" regions. These residues are referred to as "Complementarity Determining Regions" (CDRs), (figure 1). CDRs from the variable heavy and variable light chain domains are juxtaposed to create the antigen binding site that recognizes the antigenic epitope, a specific location on the antigen $[8,9]$.

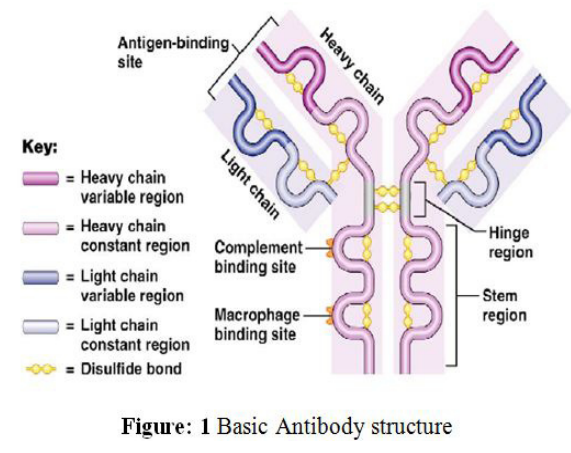

Figure: 1 Basic Antibody structure

Source: [9]

An immunoglobulin monomer molecule consists of four polypeptide chains; two identical heavy chains and two identical light chains connected by disulfide bonds. Each of these chains contains one variable domain and one constant domain [10]. Immunoglobulins are glycoprotein molecules that are produced by plasma cells in response to an immunogen. Depending on the amino acid sequence of the constant domain of their heavy chains, immunoglobulins can be assigned to different classes. There are five major classes of immunoglobulins: $\operatorname{IgA}, \operatorname{IgD}$, IgE, $\operatorname{IgG}$, and IgM. The heavy chain constant domains corresponding to different classes of immunoglobulins are called alpha, delta, epsilon, gamma, and mu, respectively [11].

Immunoglobulins function through binding specifically to one or a few closely related antigens. Each immunoglobulin actually binds to a specific antigenic determinant. Following binding to a specific antigen determinant, the immunoglobulins mediate a variety of effector functions that is required to overcome the antigen-antibody combination $[9,4]$.

\section{Early Antibody Therapies}

In the late nineteenth century, the German army doctor Emil von Behring (1854-1917), later the first Nobel Laureate for Medicine, pioneered the therapeutic application of antibodies. He used blood serum for the treatment of tetanus and diphtheria. When his data were mechanism to fight foreign toxic substances and that these substances should be present in the blood and therefore can be prepared from serum and used for therapy against toxins or infections. Antibody based (serum) therapies were first used to treat human infections in the 1890s $[12,13]$. In the early 20th century, serum therapy was used to treat a variety of bacterial infections, including those caused by Corynebacterium diphtheria, Streptococcus pneumonia, Neisseria meningitides, Haemophilus influenza, group a streptococcus, and Clostridium tetani. By the 1930s, serum therapy was standard treatment for lobar pneumonia. Several large controlled trials showed that administering type-specific serum reduced the death rate in patients with pneumococcal pneumonia by approximately $50 \%[12]$.

In order to survive in a world laden with microorganisms, most multi-cellular organisms ought to depend on a network of host defense mechanisms which in most cases, involves several levels of interacting systems. Since the initial contact of fastidious microorganisms with the host usually occurs at inner or outer body surfaces, they should be the primary site for an immune reaction to occur. Thus, innate immune responses refer to the first line of host defense, which acts within a few hours after microbial exposure to mucosal surfaces. Upon recognition of conserved molecular microbial patterns such as PAMs or Pathogen-Associated Molecular Patterns (example, LPS and cell wall components) and Toll-Like Receptors (TLR) initiate the immune responses of the host [14-16].

Using the urinary and gastro-intestinal tract as model systems, information has been obtained on how organ and cell-specific expression patterns of TLR on epithelial cells correlate to the 
ability of an organ to rapidly respond to bacterial infections has been obtained [17]. It has become clear now that understanding the innate response to pathogens will certainly provide insights to host defenses as well as the strategies used by pathogens to circumvent these defense mechanisms. Remarkably, the patternspecific recognition system already acknowledged in animals, has also been reported in plants [18]. In complex system an invading microorganism can simply be eliminated by this primary reaction the innate response without requiring an activation of the adaptive immunity [19].

If the invading microbe outgrows the innate host defense, endogenous effector mechanisms of the innate system are up-regulated and have direct antimicrobial activity and mediator function to attract inflammatory cells and cells of the adaptive immune system. In lower eukaryotes, mostly invertebrates, the adaptive system is nonexistent, thus accounting for the versatile and effective role the innate system has in order to control, by itself, the invasiveness of a given pathogen [20].

\section{Advantage of Antibody Based Therapy}

Antibody molecules are assembled from combinations of variable gene elements, and the possibilities resulting from combining the many variable gene elements in the germ line enable the host to synthesize antibodies to an extraordinarily large number of antigens. During the generation of the antibody response, somatic mutations are introduced into immunoglobulin genes, which result in higher affinity antibodies and more diversity in specificity. Thus, antibodies are, as a class, broad-spectrum antimicrobial agents with activity against all classes of pathogens. However, individual antibodies are usually pathogen-specific and can control resistant micro-organisms and no disturbances in the normal host flora [21].

Antibodies are the best option for therapy and prophylaxis of a small number of viral diseases, for which antibiotics obviously are not a treatment option. Applications include pre-exposure prophylaxis of hepatitis B and varicella as well as treatment of viral diseases for which no vaccines or specific drugs are available, such as rabies and Ebola [22]. However, also bacterial diseases are on the list of candidates for antibody therapy, especially those for which preventive or therapeutic approaches are imperfect, not available, or no longer available. Pathogens include vancomycinresistant Enterococcus, Bordetella pertussis, drug-resistant Mycobacterium tuberculosis, methicillin resistant Staphylococcus aurous, and Pseudomonas aeroginosa [22, 23,24].

Antibody therapy has an increasing number of applications in which it is possible to use inexpensive Sources of animal antibodies, such as bovine colostral antibodies and egg yolk antibodies. With the exception of the systemic administration of purified egg yolk antibodies against snake venoms [25-28], all these applications involve per oral administration of antibodies for the treatment of enteric infections, such as enterotoxicogenic E. coli, Helicobacter pylori, the dental caries causing Streptococcus mutans, and rotaviral infections [29].

Serum therapy is the administration of immune serum from immunized animals or convalescent humans for the prevention or treatment of infectious diseases, a sheep serum against diphtheria toxin [30]. Because, all that is required for efficacy of antibody treatment in the case of toxin-mediated infectious diseases is the formation of a stable immune complex between the toxin and the antibody, preventing the toxin from entering and damaging any target cells, it is not surprising that these were the first success stories of serum therapy. For instance, serum therapy reduced mortality from diphtheria from 50 to $80 \%$ to 6 to $15 \%$ [23].

Antisera against cholera vibrios could transfer immunity to control and kill the bacteria in vitro. Other examples include the immunoneutralization of tetanus toxin [31] and toxins responsible for scarlet fever (pyrogenic exotoxins) [23,32]. Although antibiotics kill microorganisms directly or interfere with their replication, antibodies use much more versatile mechanisms that include the promotion of phagocytosis at the site of infection, activation of the complement cascade followed by an inflammatory response and attraction of phagocytes, and initiation of antibody dependent cellular toxicity executed by monocytes, neutrophils, and Natural Killer (NK) cells. Its administration has the capacity to enhance immune function in immunosuppressed patients. In addition, antibodies can cause agglutination of bacteria and viruses, restrict mobility of the pathogen, and inhibit microbial metabolism and growth when binds to bacterial transporter proteins [24].

Although, the level of antibody immunity differs among pathogens, it may be possible to develop useful antibody therapies even if natural antibody immunity plays little or no role in protection. Two fungi, Candida albicans and Cryptococcus neoformans, are pathogens for which protective antibodies can be generated despite uncertainty about the role of natural antibody immunity [13]. The MAbs to C. neoformans enhance the therapeutic efficacy of amphotericin B [33,34], and 5-flucytosine. Therefore, uncertainty regarding the role of natural antibody immunity in protecting against a given pathogen does not rule out the existence of antibodies that may be useful in therapy [35].

Antibody-based therapies have low toxicities and high specificities. The high specificity of antibodies is both an advantage and a disadvantage. The advantage of high specificity is that antibodybased therapies target only the microorganism that causes disease and, it prevents development of resistance among non targeted microorganisms and avoids disturbance of the normal micro flora. In fact, in the case of serum therapy, numerous type-specific sera were developed for the treatment of pneumococcal pneumonia because only type-specific sera were effective against pneumococci $[23,33]$.

As natural products of the immune system, antibodies can 
interact with other immune components. Some mechanisms of antibody action, such as toxin and virus neutralization, complement activation, and direct antimicrobial functions, such as the generation of oxidants, are independent of other host immune components. In recent years, the recognition that antibodies can be immunomodulators, bridging the innate, acquired, cellular and humoral immune responses, has revealed new mechanisms of antibody-mediated immunity and has provided a better understanding of how and why antibodies are effective against microorganisms for which they do not mediate a direct biological effect [36].

The versatility of antibody technologies provides alternatives for countering antibody-resistant strains. For instance, new antibodies directed toward the mutated epitope could be developed, or antibodies that bind other antigenic targets could be introduced. Protease-producing strains could be countered with protease resistant immunoglobulin molecules generated by introducing amino acid changes at protease cleavage sites In addition, the use of antibodies as therapeutic reagents has the advantage that there are several isotypes, which can function therapeutically in either an intact form or as fragments. In the intact molecule, the variable region (Fab) binds antigen, whereas the constant region $(\mathrm{Fc})$ determines the biological properties of the immunoglobulin molecule, such as serum half-life, interaction with cellular Fc receptors and the ability to activate complement [37].

Historically, vaccine development for numerous infectious diseases was fuelled by antibody-based therapies and research into antibody mediated immunity. For example, successful passive antibody therapy against pneumococcal pneumonia and diphtheria preceded the development of vaccines against these diseases. More recently, the generation of protective MAbs against Cryptococcus neoformans and Candidia albicans identified polysaccharide antigens that were then used to design effective conjugate vaccines $[38,39]$.

Protective antibodies to microbial polysaccharides can be used to identify Peptide mimotopes that elicit protective antibody responses [40], and antibodies that elicit protective anti-idiotypic responses can be used directly as immunogens. Efforts to develop antibody-based therapies can, therefore, promote vaccine development [41].

\section{Limitation of Antibody Based Therapy}

Even though excellent results were obtained with the neutralization of bacterial toxins, the variability and multiplicity of bacterial epitopes posed serious problems for the use of serum therapy against the majority of bacterial diseases. This is still true today; antibodies are a superior therapeutic choice for the neutralization of toxins (the use of Antisera against snake venoms), but treatment of other bacterial diseases requires fast and accurate microbiological diagnosis followed by swift and repeated administration of an adequate dose of high quality antiserum via a route that will effectively reach the pathogen for neutralization. Indeed, there is unfortunately no such thing as an effective broad-spectrum antiserum. This requirement in most cases disqualifies antibodies as a first choice antimicrobial therapy $[23,36]$.

Narrow specificity becomes a disadvantage in cases of mixed infections that cannot be treated with a single antibody preparation; therefore more than one antibody preparation might be required to target microorganisms with high antigenic variation. It also decreases the potential market for the drug. Moreover, genetic variability and immune evasion capabilities characterize many pathogens. Next to the challenge of antibody specificity, the production cost of sufficient quantities of high quality antibodies is considerable and certainly higher than the cost of routine chemotherapy [36].

Unless intended for therapy of enteric pathogens, therapeutic antibodies need to be administered systemically. In addition, systemic administration ideally requires antibodies of the same species in order to avoid anti-isotype immune reaction against the therapeutic agent, which is an obvious obstacle in human medicine [36]. The efficacy of therapeutic antibodies diminished rapidly after the onset of symptoms. The mechanism responsible for this is not well understood, but might reflect a rapid increase in the microbial burden in the animal, which are usually selected on the basis of their marked susceptibility to the agent [42].

A loss of efficacy with increased duration of infection or disease could limit the application of antibody based prophylaxis or conditions where an early diagnosis is possible. Recent advances in diagnostic microbiology, including polymerase chain reaction and nucleic acid hybridization, could substantially shorten the time required to establish a microbiologic diagnosis. The narrow spectrum of antimicrobial activity that characterizes antibody based therapies is a drawback for its commercial development [23].

Widespread use of antibody based therapies could produce selective pressure on microbial populations for the emergence of antibody-resistant variants. Antibody-resistant mutants of Borrelia burdorferi have been produced in the laboratory [43], and may be selected in patients who undergo antibody based therapies. Microorganisms may become resistant to antibodies by acquiring mutations that change the antigenic site recognized by the antibodies or by producing proteases that destroy immunoglobulins [44].

\section{Veterinary Use of Antibody as Maternal Extension}

Antibody therapy and prophylaxis have a natural place in animal agriculture for the simple reason that mammalian species such as pigs, horses, sheep, and cows do not transmit maternal immunity prenatally (antibodies do not cross the barrier of the placenta, as is the case in humans) but postnatally through colostral antibodies. In poultry, maternal antibodies are transmitted to the offspring via the yolk of the eggs [29,45-49]. As a consequence, colostrums and egg yolk were the first (and to the best of our knowledge still 
the only) sources of antibodies that are routinely used for prophylaxis and therapy of infectious diseases in an agricultural setting, for which cost of antibody production, antibody production capacity, and simplicity of administration (i.e., orally, through the feed) are critical factors. Bovine colostrum and chicken egg yolks have indeed evolved naturally as antibody carriers per excellence, and colostrum was recognized as a vehicle for immune factors. During colostrum formation, immunoglobulins are transported across the secretory epithelium of the mammary gland by specific, receptormediated transport at a rate of as much as $500 \mathrm{~g} / \mathrm{wk}$. First colostrum contains between 30 and $200 \mathrm{mg}$ of immunoglobulin per milliliter, the majority (75\%) of which is IgG1 [46].

In a similar fashion, circulating antibodies in the plasma of a laying hen are transported by the granulosa cell layer and deposited into the yolk during the last days of oogenesis. An egg can contain as much as $25 \mathrm{mg}$ of $\operatorname{IgY}$ per milliliter of yolk [50]. Antigen specific avian antibodies (IgY) have been used for numerous applications in medical and research fields. One of the most valuable and promising areas of its potential to be used for passive immunization to treat and prevent human and animal infections [51].

However, its clinical applications in humans are very scarce. But it is the functional equivalent to mammalian IgG and is the predominant immunoglobulin in egg yolk and also, actively transferred from the serum of the hen into the egg yolk to give immunity to embryos and chickens. This corresponds to placental IgG transfer in mammals to provide immunity to the fetus. The overall structure of avian $\mathrm{IgY}$ is similar to mammalian $\mathrm{IgG}$, with two heavy and two light chains. A hen usually lays $\sim 280$ eggs in a year and an egg yolk contains 100-150 mg of IgY antibodies. This results in a yield of 28-42 $\mathrm{g}$ IgY per year per hen [52].

When a hen is vaccinated against a microbe, around 5\%-10\% of the IgY will react to this microbe. The production is simple, efficient and economical. It involves separation of the egg yolk from the white, followed by purification of antibodies from lipids and other materials. Therapeutic use can be produced from the egg yolk without any other ingredients than sterile water. It is stable at pH 4-9 and up to $65^{\circ} \mathrm{C}$ in aqueous condition. High salt conditions and stabilizing reagents (example, sucker) increases the stability to heat, acidic $\mathrm{pH}$ and high pressure. It can be easily administered orally for the treatment of gastrointestinal infections [53].

A fraction of immunoglobulins retain their neutralization activity in various segments of the gastrointestinal tract. A stronger activity would be easy to accomplish by buffers or in acid resistant capsules. This is the case only for the first 2 to 3 day of life; beyond this point uptake of intact antibodies no longer occurs, and any beneficial effects of antibody treatment need to be within the limits of the gastrointestinal environment. Those include challenges such as the acidic $\mathrm{pH}$ of the stomach and the presence of proteolytic en- zymes; thus, natural transfer of maternal immunity is limited to the first couple of days of life. Without, human interference, per oral administration of antibodies beyond the time of enteric antibody absorption can indeed be quite effective [54].

\section{Successful Application of Colostral and Egg Yolk Anti- bodies}

The bulk of antibody treatment with colostrum and egg derived antibodies involves per oral treatment of enteric pathogens [47,55]. Applications are very similar in humans and in agricultural species; in principle, colostral antibodies and egg yolk antibodies seem to be used interchangeably. The best known examples include, the treatment of enterotoxigenic E. coli (ETEC) in humans [56], pigs [57], and calves [58], the dental caries causing bacteria Streptococcus mutans in humans $[59,60]$, fatal salmonellosis in calves [61], and the treatment of gastric infections with Helicobacter pylori in humans $[62,63]$. Also enteric viral diseases are currently treated successfully with colostral or egg yolk antibodies. Those include rotaviral infections in humans [64,65], calves [66], and piglets [67] and corona viral infections in calves [68].

\section{Limitations of Antibody Therapy in an Agricultural Context}

Although the benefits of feed supplementation with pathogen-specific antibodies from hyper-immune colostrums and egg yolk are undisputed, it would be an exaggeration to call oral antibody therapy common practice, especially in an agricultural context. This undoubtedly has to do with the fact that production of standardized immune colostrum and egg yolk therapeutics, although theoretically and technically relatively simple, is labor intensive and, thus, cost intensive. As a consequence, these therapeutics are not used on a general scale (example, like antibiotics or vitamin and mineral supplements), and treatment of individual animals on a case by case basis represents an additional obstacle [29].

There is still a widespread misconception, that orally administered antibodies simply get digested and inactivated in the gastrointestinal tract, just like any other protein. Consequently, orally administered antibodies are not viewed as very effective drugs, at least not compared with small, simple, and stable molecules such as antibiotics. Although, it is true that orally administered antibodies are subjected to potential denaturation by the acidic $\mathrm{pH}$ of the stomach and degradation by proteases, active antibodies can still be detected in stool samples in percentages varying from very low levels to as much as $50 \%$ of the orally administered dose [29].

Studies have shown that parts of the antibodies remain intact in pepsin and trypsin digests, but there is considerable cleavage of the antibodies into Fab and $\mathrm{F}\left(\mathrm{ab}^{\prime}\right) 2$ fragments. It is important to note that these fragments still have the capability to bind to the antigen and display neutralizing activity. However, they may largely escape detection methods that depend on the presence of the anti- 
body's Fc fragment that carries most of the isotypic determinants recognized by secondary reagents [69]. In addition, it is possible to administer antibodies in a stomach resistant formula in order to increase the ratio of intact antibodies in the intestine [70].

\section{Application of Antibody Engineering in Veteri- nary Medicine}

To avoid or reduce different kinds of losses due to animal disease cost, animal scientists are using biotechnology to develop an array of products to diagnose, treat (Table 1), and prevent disease in farm animals. Many animal diseases are difficult to diagnose. However, using biotechnology, scientists are developing fast, accurate diagnostic tests for many of the most common farm animal diseases and many of these new tests use monoclonal antibodies [71].

These antibodies are able to differentiate specifically those microbes that cause disease and that are vaccines. Example, veterinary clinicians and farmers use monoclonal antibodies to diagnose brucellosis in pregnant cattle, and then to prevent the spread of this infection by isolating carrier individuals from the rest of the herd. Monoclonal antibodies test also used for the diagnosis and treatment (by feeding it to calves or piglets that coat the offending bacteria then preventing the microbes from causing diarrhea) of scours in calves and piglets, to detect pregnancy [72].

\begin{tabular}{|c|}
\hline Antibody Format Application Reference \\
\hline $\begin{array}{c}\text { scFv Hepatocellular carcinoma therapy [73] } \\
\mathrm{dsFv} \text { Cytotoxic recombinant anti-mesothelin [74] } \\
\text { immunotoxin }\end{array}$ \\
Anti CD22 recombinant immunotoxin in [75] \\
chemotherapy of resistant hairy cell leukemia \\
Fab Anti-platelet iib/iiia inhibition of platelet [76] \\
aggregation \\
Shiga toxin 1 neutralization [77]
\end{tabular}

Table1: Various Antibody Format and Biotechnological or Therapeutic Application.

Source: Brichta [78].

Genetic engineering is also useful in generating large quantities of therapeutic proteins through inserting one or more new genes that are able to produce a natural disease fighting protein in to an animal (Figure 2). Interferon and interlukin-2 are natural proteins and are generated through genetic engineering to kill viruses and also to stimulate the animal's immune system, improving the immune system's ability to fight a disease. Antibody engineering technology is also used in the production of vaccines for swine pseudo rabies, a fatal herpes virus disease and for foot and mouth disease [79].

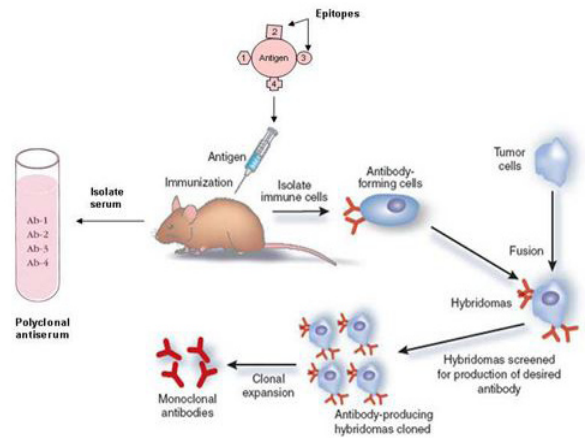

Figure 2: Overview of poly- and monoclonal antibody production.

Source: [80].

Since the introduction of hybridoma technology, it is becoming possible to accurately diagnose different protozoal and parasitic helminth infections of animals with the help of monoclonal antibodies that is specifically bind to specific epitope of the parasite antigen. Thus, monoclonal antibodies are able to accurately characterize and localize the parasitic antigen to the species level with the help of ELISA, PCR, radio immune assay and fluorescent immunoassay. Certain protozoal (Coccidiosis, Babesiosis, Theileriosis, Toxoplasmosis and Cryptosporidiosis) and helminth (Fasciolosis, Diroflariosis, Trichinosis, and Cystic Echinococcosis) diseases of animals can be diagnosed accurately and treated with the help of monoclonal antibodies $[81,82]$.

\section{Monoclonal Antibodies}

Monoclonal antibodies are antibodies that can recognizes a single and unique antigen surfaces specifically an epitope of an antigen and helps in the diagnosis of diseases caused by different pathogens [9]. The monoclonal antibodies being directed against single epitopes are homogeneous, highly specific and can be produced in unlimited quantities. Advances in genetic engineering over the years have provided numerous ways to design MAbs that are more robust and efficacious [83]. These are produced by fusing a cancerous cell with a cell that produces an antibody. Scientists create a hybridoma, which produces large quantities of identical or monoclonal antibodies in a pure, highly concentrated form. They produce these molecules by fusing two kinds of cells; one is an immune system cell that produces antibodies, which bind to part of a particular disease causing microbe; the other is a cancer cell $[53,83,84,85]$.

\section{Uses of Monoclonal Antibodies}

Monoclonal antibodies or specific antibodies are now an essential tool of much biomedical research and are of great com- 
mercial and medical value. Their uses are numerous and include prevention, diagnosis, and treatment of disease. They are especially useful in distinguishing morphologically similar lesions, like pleural and peritoneal mesothelioma, adenocarcinoma and in the determination of the organ or tissue origin of undifferentiated metastases, and also help in the detection of accult metastases by immuno-cytological analysis of bone marrow, other tissue aspirates, as well as lymph + nodes and other tissues [86].

In animal disease diagnosis, they are very useful for identification and antigenic characterization of pathogens. They have also tremendous application in the field of diagnostics, therapeutics and targeted drug delivery systems, not only for infectious diseases caused by bacteria, viruses, and protozoa but also for cancer, metabolic and hormonal disorders [53]. Monoclonal antibodies can react with a single antigenic determinant and this restricted reactivity allows for precise identification of organism of interest which is the major advantage of MAbs over polyclonal Antisera. In case of a pathogen occurring as subtype defined by unique antigenic differences, specific MAbs can be used. Monoclonal antibodies are not used extensively in the animal world. They are employed in the process of genetically engineering an animal vaccine and are used mainly in the production of vaccines. Viruses, such as foot and mouth disease, are composed of large and complex proteins, all of which have many antibody binding sites [86].

Another use of monoclonal antibodies is a potential therapeutic role in preventing certain infectious diseases and some parasitic diseases. In this case, monoclonal antibodies that bind to hair like binding sites of the antigen of certain strains of intestinal bacteria, such as Escherichia coli (E.coli) are fed to new born calves or pigs. Then the bacteria will become to bind to the gut wall and then this will reduces the severity of the disease [9].

\section{Polyclonal Antibodies}

Polyclonal antibodies (Pabs) are produced by multiple B-cell clones, and as a population can recognize and bind with varying affinities to a variety of independent epitopes on a single antigen [60]. In a typical antiserum, only 5\% of the Pabs are target-specific. Serum is a very good source of polyclonal antibodies. Further purification may be required, either to isolate the group of polyclonal antibodies or to isolate a specific antibody from the group [87,88].

The presence of several antibodies directed at different epitopes of the same antigen makes elution difficult and may damage the chromatography column and denature the antigen. Pabs are commonly obtained from sera of immunized animals, and are thus available in limited supply; it is often difficult to obtain multiple lots with consistent quality. To avoid these problems, it can be purified by affinity chromatography over a column of antigen to obtain antigen specific antibodies [89].

\section{Conclusion and Recommendations}

Normally, Antibodies are one of the most important B-cell Receptors that can be used as therapeutic and prophylactic treatment of infectious, non-infectious and parasitic disease those resistant to antibiotics and susceptible as well. Even though, the availability of many isotypes of immunoglobulins is not sufficient at everywhere and not used on general scale. Its therapy has an increasing number of applications in which it is possible to use inexpensive sources of animal antibodies, such as bovine colostral antibodies and egg yolk antibodies. But its use is less than expected value still in developing countries including Ethiopia.

Based up on the above conclusion, the following recommendations are forwarded:

- Awareness creation about importance of antibodies to developing countries is very beneficial.

- It is superior, if isotypes of immunoglobulins is well available on market and used on general scale.

- It is better if therapeutic and prophylactic antibodies are considered rather than antibiotics.

\section{References}

1. Aarestrup FM (2000) Occurrence, selection and spread of resistance to antimicrobial agents used for growth promotion for food animals in Denmark. APMIS Suppl 101: 1-48.

2. Stefan D, Janice M (2014) Therapeutic Antibodies from past to future. Wiley$\mathrm{VCH}$ Verlag $\mathrm{GMbH}$ and $\mathrm{Co} \mathrm{KGaA}$.

3. Warr GW, Magor KE. Higgins DA (1995) IgY: clues to the origins of modern antibodies. Immunol Toda 16: 392-398.

4. Tizard Ian R (2004) Veterinary immunology an Introduction, Seventh edition.

5. Pier GB, Lyczak JB, Wetzler LM (2004) Immunology, Infection, and Immunity. ASM Press 246-255.

6. Borghesi L, Milcarek C (2006) "From B cell to plasma cell: regulation of V (D) J recombination and antibody secretion". Immunol. Res 36: 27-32.

7. Gemechu C, Birhanu H, Aynalem M (2015) A Review on Antibody Engineering for Development of Therapeutic Antibodies. International Journal of Immunology 3: 27-36.

8. Elgert KD (1996) Antibody Structure and Function in Immunology: Understanding the Immune System, Wiley-Liss 58-78.

9. Kindt TJ, Goldsby RA, Osborne BA, Kuby J (2007) Kuby Immunology, W.H. Freeman and Company New York.

10. Barclay A (2003) "Membrane proteins with immunoglobulin-like domains a master super family of interaction molecules". Semin Immunol 15: 215-223.

11. Roux K (1999) "Immunoglobulin structure and function as revealed by electron microscopy". Int Arch Allergy Immunol 120: 85-99.

12. Casadevall A, Scharff MD (1994) "Serum therapy" revisited: animal models of infection and the development of passive antibody therapy. Agents Chemother 38: 1695-1702. 
13. Casadevall A (1995) Antibody immunity and invasive fungal infections 63: 4211-8232.

14. Aderem A, Ulevitch R (2000) Toll-like receptors in the induction of the innate immune response. Nature 406: 782-7874.

15. Akira S, Takeda K, Kaicho T (2001) Toll-like receptors: Critical proteins linking innate and acquired immunity. Nature Immunology 2: 675-680.

16. Hoffmann JA, Kafatos FC, Janeway CA, Ezekowitz RA (1999) Phylogenetic perspectives in innate immunity. Science 284: 1313-1318.

17. BŠckhed F, Sšderhšll M, Ekman P, Normark S, Richter-dahlfors A (2001) Induction of innate immune responses by E. coli and purified LPS correlate to organ- and cell-specific expression of Toll-like receptors within the human urinary tract. Cellular Microbiology 3: 153-158.

18. Dangl JL, Jones JD (2001) Plant pathogens and integrated defense responses to infection. Nature 411: 826-833.

19. Bals R (2000) epithelial antimicrobial peptides in host defense against infection (Review). Respiratory Research 1: 141-150.

20. Otvos LJ (2000) Antibacterial peptides isolated from insects. Journal of Peptide Sciences 6: 497- 511.

21. French DL, Laskov R, Scharff MD (1989) the role of somatic hyper mutation in the generation of antibody diversity. Science 244: 1152-1721.

22. Keller MA, Stiehm ER (2000) Passive immunity in prevention and treatment of infectious diseases. Clin. Microbiol. Rev 13: 602-614.

23. Buchwald UK, Pirofski L (2003) Immune therapy for infectious diseases at the dawn of the 21st century: The past, present and future role of antibody therapy, therapeutic vaccination and biological response modifiers. Curr. Pharm. Des 9: 945-968.

24. Oral HB, Ozakin C, Akdis CA (2002) back to the future: Antibody-based strategies for the treatment of infectious diseases. Mol. Biotechno 21: 225239.

25. Almeida CM, Kanashiro MM, Rangel Filho FB, Mata MF, Kipnis TL (1998) Development of snake antivenom antibodies in chickens and their purification from yolk. Vet. Rec 143: 579-584.

26. Carroll SB, Thalley BS, Theakston RD, Laing G (1992) Comparison of the purity and efficacy of affinity purified avian antivenoms with commercial equine crotalid antivenoms. Toxic on 30: 1017-1025.

27. Devi CM, Bai MV, Lal AV, Umashankar PR, Krishnan LK (2002) An improved method for isolation of antivipervenom antibodies from chicken egg yolk. J. Biochem. Biophys. Methods 51: 129-138.

28. Thalley BS, Carroll SB (1990) Rattle snake and scorpion antivenoms from the egg yolks of immunized hens. Biotechnology (N. Y) 8: 934-938.

29. Carlander D, Kollberg HP, Wejaker PE, Larsson A (2000) per oral immuno therapy with yolk antibodies for the prevention and treatment of enteric infections. Immunol. Res 21:1-6.

30. Winau F, Winau R (2002) Emil von Behring and serum therapy. Microbes Infect 4: $185-188$

31. Grundbacher FJ (1992) Behring's discovery of diphtheria and tetanus antitoxins. Immunol 13:188-190.

32. Weisse ME (2001) the fourth disease, 1900-2000. Lancet 357: 299-301.
33. Mukherjee J, Zuckier LS, Scharff MD, Casadevall A (1994) Therapeutic efficacy of monoclonal antibodies to Cryptococcus neoformans glucuronoxylomannan alone and in combination with amphotericin B. Antimicrob. Agents Chemother 38: 580-587.

34. Dromer F, Charreire J (1991) Improved amphotericin B activity by a monoclonal anti-Cryptococcus neoformans antibody: study during murine cryptococcosis and mechanisms of action. J Infect Dis 163: 1114-1120.

35. Casadevall A. Feldmesser M, Mukherjee J (1996) Combination of 5-flucytosine and capsule binding monoclonal antibody in therapy of murine Cryptococcus neoformans infections and in vitro 37: 617-622.

36. Casadevall A, Pirofski LA (2003) Antibody-mediated regulation of cellular immunity and the inflammatory response. Trends Immunol 24: 474-478.

37. Samulsson A, Towers TL, Ravetch JV (2001) Anti-inflammatory activity of IVIG mediated through the inhibitory Fc receptor. Science 291: 484-486.

38. Devi SJ (1996) Preclinical efficacies of a glucuronoxylomannan-tetanus toxoid conjugate vaccine of Cryptococcus neoformans in a murine model. Vaccine 14: 841-842.

39. Han Y, Ulrich MA, Cutler JE (1999) Candida albicans Mannan Extract-Protein Conjugates Induce a Protective Immune Response against Experimental Candidiasis 179: 1477-1484.

40. Pirofski L (2001) Polysaccharides, mimotopes and vaccines for fungal and encapsulated pathogens. Trends Microbiol. 9: 445-451.

41. Polonelli L, De Bernardis F, Conti S, Boccanera M, Gerloni M (1994) Idiotypic intravaginal vaccination to protect against candidal vaginitis by secretory, yeast killer toxin-like anti-idiotypic antibodies. J. Immunol 152: 3175 3182.

42. Robbins JB, Schneerson R, Szu SC (1995) Perspective: hypothesis: serum IgG antibody is sufficient to confer protection against infectious diseases by inactivating the inoculum. J. Infect. Dis 171: 1387-1398.

43. Sadziene A, Rosa PA, Thompson PA, Hogan DM, Barbour AG (1992) Antibody-resistant mutants of Borrelia burgdorferi. J Exp Med 176: 799-809.

44. Halter R, Pohlner J, Meyer TF (1989) Mossaic-like organization of IgA protease genes in Neisseria gonorrhoeae generated by horizontal genetic exchange in vivo. Embo J 8: 2737-2744.

45. Barrington GM, Parish SM (2001) Bovine neonatal immunology. Vet. Clin 17: $463-476$

46. Korhonen H, Marnila P, Gill HS (2000b) Milk immunoglobulins and complement factors. Br. J. Nutr 84: 75-80.

47. Korhonen H, Marnila P, Gill HS (2000a) Bovine milk antibodies for health. Br. J. Nutr 84: 135-146.

48. Mine Y, Kovacs-Nolan J (2002) Chicken egg yolk antibodies as therapeutics in enteric infectious disease. J. Med. Food 5: 159-169.

49. Van de Perre P (2003) Transfer of antibody via mother's milk. Vaccine 21: 3374-3376.

50. Rose ME, Orlans E, Buttress N (1974) Immunoglobulin classes in the hen's egg: Their segregation in yolk and white. Eur. J. Immunol 4: 521.

51. Hatta H, Ozeki M, Tsuda K (1997a) Egg yolk antibody IgY and its application. Their Basic and Applied Science 151-178.

52. Akita E, Nakai S (1992) Immunoglobulins from egg yolk: Isolation and purification. J Food Science 57: 629-634. 
Citation: Yimer L, Mideksa K, Ferede B (2017) Review on Antibody as a Drug of Choice. Arch Vet Sci, 2017: VST-112.

53. Nelson PN, Reynolds GM, Waldron EE, Ward E, Giannopoulos K, et al. (2000) "Demystified Monoclonal antibodies". Molecular pathology 53: 111-117.

54. McFadden TB, Besser TE, Barringon GM (1997) Regulation of immunoglobulin transfer into mammary secretions of ruminants. G. Prosser, ed. CAB International 133-152.

55. Carlander D, Kollberg H, Larsson A (2002) Retention of specific yolk IgY in the human oral cavity. Bio Drugs 16: 433-437.

56. Freedman DJ, Tacket A, Delehanty DR, Maneval J, Nataro J, et al. (1998) Milk immunoglobulin with specific activity against purified colonization factor antigens can protect against oral challenge with enterotoxigenic Escherichia coli. J. Infect. Dis 177: 662-667.

57. Owusu-Asiedu A, Nyachoti CM, Baidoo SK, Marquardt RR, Yang X (2003) Response of early-weaned pigs to an enterotoxigenic Escherichia coli K88 challenge when fed diets containing spray-dried porcine plasma or pea protein isolate plus egg yolk antibody. J. Anim. Sci 81: 1781-1789.

58. Ikemori Y, Kuroki M, Peralta RC, Yokoyama H, Kodama Y (1992) Protection of neonatal calves against fatal enteric colibacillosis by administration of egg yolk powder from hens immunized with K99-piliated enterotoxigenic Escherichia coli. Am. J. Vet. Res 53: 2005-2008.

59. Filler SJ, Gregory RL, Michalek SM, Katz J, McGhee JR (1991) Effect of immune bovine milk on Streptococcus mutans in human dental plaque. Arch. Oral Biol 36: 41-47.

60. Hatta H, Tsuda K, Ozeki M, Kim M, Yamamoto T, et al. (1997b) Passive immunization against dental plaque formation in humans: Effect of a mouth rinse containing egg yolk antibodies IgY specific to Streptococcus mutans. Caries Res 31: 268-274.

61. Yokoyama H, Peralta RC, Umeda K, Hashi T, Icatlo FC, et al. (1998) Prevention of fatal salmonellosis in neonatal calves, using orally administered chicken egg yolk Salmonella-specific antibodies. Am. J. Vet. Res 59: 416420.

62. Shimamoto CS, Tokioka I, Hirata H, Tani H, Ohishi, et al. (2002) Inhibition of Helicobacter pylori infection by orally administered yolk-derived anti-Helicobacter pylori antibody. Hepato gastro enterology 49: 709-714.

63. Shin JH, Yang M, Nam SW, Kim JT, Myung NH, et al. (2002) Use of egg yolkderived immunoglobulin as an alternative to antibiotic treatment for control of Helicobacter pylori infection. Clin. Diagn. Lab. Immunol 9: 1061-1066.

64. Ebina T, Sato A, Umezu K, Ishida N, Ohyama S, et al. (1983) Prevention of rotavirus infection by cow colostrum antibody against human rotaviruses. Lancet 2: 1029-1030.

65. Ebina T, Sato A, Umezu K, Ishida N, Ohyama S, et al. (1985) Prevention of rotavirus infection by oral administration of cow colostrum containing antihumanrotavirus antibody. Med. Microbiol. Immunol. Ber 174: 177-185.

66. Kuroki M, Ohta M, Ikemori Y, Peralta RC, Yokoyama H, et al. (1994) Passive protection against bovine rotavirus in calves by specific immunoglobulins from chicken egg yolk. Arch. Virol 138: 143-148.

67. Hennig-Pauka I, Stelljes I, Waldmann KH (2003) Studies on the effect of specific egg antibodies against Escherichia coli infections in piglets. Dtsch. Tierarztl. Wochenschr 110: 49-54.

68. Ikemori Y, Ohta M, Umeda K, Icatlo FC, Kuroki JM, et al. (1997) Passive protection of neonatal calves against bovine coronavirus-induced diarrhea by administration of egg yolk or colostrum antibody powder. Vet. Microbiol 58: 105-111.

69. Kuby J (1992) Immunoglobulins: Structure and function. In Immunology. W. H. Freeman and Company, New York 111.
70. Reilly RM, Domingo R, Sandhu J (1997) Oral delivery of antibodies. Future pharmacokinetic trends. Clin. Pharmacokinet 32: 313-323.

71. GellertMV(2002)Recombination:RAGproteins, repairfactors, andregulation.

72. Vaccaro DE, Markinac JE (1995) Use of monoclonal antibodies with particles to separate cell subpopulations by positive selection. Methods Mol Biol 45: 2539.

73. Yeung A, Aloman C, Wittrup D, Wands JR (2004) Antibody-directed therapy for human hepatocellular carcinoma. Gastroenterology 127: 225-231.

74. Li Q, Verschraegen CF, Mendoza J, Hassan R (2004) Cytotoxic activity of the recombinant anti-mesothelin immunotoxin, SS1 (dsFv)PE38, towards tumor cell lines established from ascites of patients with peritoneal me $\neg$ sotheliomas. Anticancer Research 24: 1327-1335.

75. Kreitman RJ, Wilson WH, Bergeron K, Raggio M, Stetler-Stevenson M, et al. (2001) Efficacy of the anti-CD22 recombinant immunotoxin BL22 in chemotherapy-resistant hairy-cell leukemia. New England Journal of Medicine 345: 241-247.

76. Yang YC, Lai CN, Wang Y, Shen BF, Li Y (2004) Expression of antibody Fab against platelet IIb/IIIa in E.coli and characterization of its biological activity. Xi Bao Yu Fen Zi Mian Yi Xue Za Zhi 20: 563-567.

77. Inoue K, Itoh K, Nakao H, Takeda T, Suzuki T (2004) Characterization of a Shiga toxin 1-neutralizing re $\neg$ combinant Fab fragment isolated by phage display system. The Tohoku Journal of Experimental Medi־cine 203: 295-303.

78. Brichta J, Hnilova M, Viskovic T (2005) Generation of hapten specific recombinant antibodies: antibody phage display technology: a review. Vet. Med- Czech 50: 231-252.

79. Gamble HR, Anderson WR, Graham CE, Murell KD (1983) Monoclonal antibody-purified antigen for the immune diagnosis of trichinosis. Am. J. Vet. Res 45: 67.

80. Michnick SW, Sidhu SS (2008) Submitting antibodies to binding arbitration. Nat Chem 4: 326-329.

81. Craig PS, Hocking RE, Mitchell GF, Rechard MD (1981) Murine hybridomaderived antibodies in the processing of antigens for the immune diagnosis of Echinococcus granulosus infection in sheep. Parasitology 83: 303-317.

82. Danforth HD (1986) Use of hybridoma antibodies combined with genetic engineering in the study of protozoan parasites: A review. In: L.P.Joiner, P.L. Long and L. R. McDongald (Ed.) proc. Georgia coccidiosis conf 574.

83. Lyer YS, Vasantha k, Manisha P, Jadhav S, Gupte SC, et al. (2006) Production of murine monoclonal anti-B. Indian J Med Res 123: 561- 564.

84. Pasqualini R, Wadih A (2004) Hybridoma-free generation of monoclonal antibodies, pans 101: 257-259.

85. Spada S, Krebber C, Pluckthun A (1997) selectively infective phages (SIP) technology. Biol. Chem 378: 445-456.

86. Maynard JA, Maassen CB, Leppla SH, Brasky K, Patterson JL (2002) Protection against anthrax toxin by recombinant antibody fragments correlates with antigen affinity. Nat. Biotechnol 20: 597-601.

87. Harlow E, Lane D (1999a) Antibody Structure and Function. Cold Spring Harbor laboratory Press 1-20.

88. Harlow E, Lane D (1999b) Antibody-Antigen Interactions. Cold Spring Harbor laboratory Press 21-37.

89. Agaton C, Falk R, Hoiden G, Gostring L, Uhlen M, et al. (2004) Selective enrichment of monospecific polyclonal antibodies for antibody-based proteomics efforts. J Chromatogr A 1043: 33-40. 